\title{
High-density genetic linkage map construction and cane cold hardiness QTL mapping for Vitis based on restriction site- associated DNA sequencing
}

Kai Su${ }^{1}$, Huiyang Xing ${ }^{1}$, Yinshan Guo ${ }^{1,2^{*}}$, Fangyuan Zhao ${ }^{1}$, Zhendong $\mathrm{Liu}^{1}$, Kun $\mathrm{Li}^{1}$, Yuanyuan $\mathrm{Li}^{3}$ and Xiuwu Guo ${ }^{1,2^{*}}$

\begin{abstract}
Background: Cold hardiness is an important agronomic trait and can significantly affect grape production and quality. Until now, there are no reports focusing on cold hardiness quantitative trait loci (QTL) mapping. In this study, grapevine interspecific hybridisation was carried out with the maternal parent 'Cabernet sauvignon' and paternal parent 'Zuoyouhong'. A total of 181 hybrid offspring and their parents were used as samples for restriction-site associated DNA sequencing (RAD). Grapevine cane phloem and xylem cold hardiness of the experimental material was detected using the low-temperature exotherm method in 2016, 2017 and 2018. QTL mapping was then conducted based on the integrated map.

Results: We constructed a high-density genetic linkage map with 16,076, 11,643, and 25,917 single-nucleotide polymorphism (SNP) markers anchored in the maternal, paternal, and integrated maps, respectively. The average genetic distances of adjacent markers in the maps were $0.65 \mathrm{cM}, 0.77 \mathrm{cM}$, and $0.41 \mathrm{cM}$, respectively. Colinearity analysis was conducted by comparison with the grape reference genome and showed good performance. Six QTLs were identified based on the phenotypic data of 3 years and they were mapped on linkage group (LG) 2, LG3, and LG15. Based on QTL results, candidate genes which may be involved in grapevine cold hardiness were selected.

Conclusions: High-density linkage maps can facilitate grapevine fine QTL mapping, genome comparison, and sequence assembly. The cold hardiness QTL mapping and candidate gene discovery performed in this study provide an important reference for molecular-assisted selection in grapevine cold hardiness breeding.
\end{abstract}

Keywords: Grapevine, Single-nucleotide polymorphism marker, Restriction-site associated DNA sequencing, Cold hardiness, Quantitative trait loci mapping, Molecular breeding

\section{Background}

Grapevine $(2 \mathrm{n}=38)$ is perennial deciduous vine fruit liana which belongs to the genus Vitis of the Vitaceae family and has high economic and social values. In 2016,

\footnotetext{
* Correspondence: grapeguo@yeah.net; guoxw1959@163.com 'College of Horticulture, Shenyang Agricultural University, Shenyang, P.R. China

Full list of author information is available at the end of the article
}

the cultivated area of grapevine in China was 847,000 ha with a total production of 13.1 million tons, accounting for $15.1 \%$ of the world's grape output (http://www.fao. org/faostat/zh/\#home). Vitis vinifera L. is the major cultivated grapevine species in China as table grapes and is a preferred raw material for making vine. Vitis vinifera L. is originated in the Mediterranean region where the climate is hot and dry in the summer and warm and

(c) The Author(s). 2020 Open Access This article is licensed under a Creative Commons Attribution 4.0 International License, which permits use, sharing, adaptation, distribution and reproduction in any medium or format, as long as you give appropriate credit to the original author(s) and the source, provide a link to the Creative Commons licence, and indicate if changes were made. The images or other third party material in this article are included in the article's Creative Commons licence, unless indicated otherwise in a credit line to the material. If material is not included in the article's Creative Commons licence and your intended use is not permitted by statutory regulation or exceeds the permitted use, you will need to obtain permission directly from the copyright holder. To view a copy of this licence, visit http://creativecommons.org/licenses/by/4.0/. The Creative Commons Public Domain Dedication waiver (http://creativecommons.org/publicdomain/zero/1.0/) applies to the data made available in this article, unless otherwise stated in a credit line to the data. 
rainy in the winter. However, China is located in typical continental monsoon climate region where cold and dry in winter. The annual lowest temperature of most grapeproducing regions in China below $-15^{\circ} \mathrm{C}$, thus it is necessary for grapevine to be buried with soil to resist the cold environment. This strategy greatly increases management costs and can also lead to the damage to the grapevine and soil structure, causing dust storms and soil erosion.

Plants usually undergo cold stress when temperatures fall below $-10^{\circ} \mathrm{C}$. Injury is associated with a complex array of cellular dysfunctions, and symptoms include loss of vigour, wilting, chlorosis, sterility, and even death [1]. Wild Vitis species such as North American (V. riparia Michx., V. labrusca L., V. rupestris Scheele.) and Asian ( $V$. amurensis Rupr.) species show significant cold hardiness, tolerating $-30{ }^{\circ} \mathrm{C}$ or even lower [2]. These wild Vitis species have been used in grapevine breeding programs for the selection of new cold hardiness cultivars. However, grapevine is a highly heterozygous species with a long developmental period and complex genetic background [3]. An alternative strategy is cultivating cold hardiness resistance cultivars through traditional crossbreeding. While traditional crossbreeding was lengthy and had lower breeding efficiency in the past. In recent years, marker-assisted selection (MAS) was widely used for the research of grape breeding based on genetic linkage map construction and QTL mapping. This strategy will make grapevine breeding more efficient and precise [3-6].

The strategy of genetic map construction in fruit trees was based on the theory of double pseudotest cross, and most of the materials used were F1 hybrid populations [7]. Single-nucleotide polymorphisms (SNPs) are codominant marker types with high genetic stability and available for their accurate detection. In recent years, with the development of next-generation sequencing (NGS) technology, simplified genome sequencing based on this technology has been widely used for identifying SNP markers and constructing grapevine genetic maps $[5,6$, 8-13]. As one of the major simplified genome sequencing technologies, restriction-site associated DNA sequencing (RAD) has been widely used in genetic map construction for grapevine and other species $[9,12,14-$ 21]. Until now, many QTLs and SNP markers related to important quantitative traits of grapevine were identified by using biparental mapping and genome-wide association study (GWAS). They were used to investigate diseases resistance genes related to powdery mildew [10, 22-25], downy mildew [6, 25-28], Pierce's disease [2931], grape phylloxera [5] and phomopsis disease [32]. They have also been used to identified genes related to a series of agronomic traits such as berry size and weight, firmness, sugars and acids content, color, muscat flavor
[33-44], architecture of the grapevine cluster [45], fruit yield and quality [46, 47], seed weight and number [48], flower sex [26, 30, 49, 50], fertility [51], inflorescence morphology [26], timing and duration of flowering and of veraison $[34,52]$.

No studies have focused on QTL mapping of grape cane cold hardiness. In this study, after years of field observation, $V$. vinifera $\mathrm{L}$. cultivar 'Cabernet sauvignon' showed weak cold hardiness and cultivar 'Zuoyouhong' which was obtained by crossing of $V$. vinifera $\times V$. amurensis showed high cold hardiness. Interspecific hybridization was then conducted and 'Cabernet sauvignon' was used as the maternal parent and 'Zuoyouhong' was used as the paternal parent. RAD sequencing and marker development were conducted based on two parents and 181 hybrid offspring. A high-density linkage map was constructed, and cane cold hardiness QTL mapping was carried out considering with 3 years of cold hardiness phenotype data. This study will provide a foundation for MAS in grapevine cane cold hardiness breeding.

\section{Results}

\section{Cane cold hardiness analysis}

Grapevine cane samples from 2016, 2017, and 2018 of the two parents and 181 individuals were identified by differential thermal analysis. Lethal temperature of phloem (LTP) and lethal temperature of xylem (LTX) during these 3 years were named as PH16, XY16, PH17, XY17, PH18, and XY18 (Additional file 1: Data S1). These values (mean value of three replicates per genotype) showed continuous variation, indicating the grapevine cold hardiness as a typical quantitative trait controlled by polygenes. Based on Shapiro-Wilk tests, these values from LTP and LTX during 3 years showed a non-normal distribution $(P<0.05)$. The correlation coefficients of LTP and LTX values in the same year were significant at $P<0.001$ and ranged from 0.24 to 0.50 . For LTP and LTX in three different years, PH16, PH17, and $\mathrm{XY} 16, \mathrm{XY} 17$ showed significance at $P<0.001$ and ranged from 0.25 to 0.47 , PH16 and PH18 showed significance at $P<0.05$ with a correlation coefficient of 0.16 . In addition, PH16 and XY17, XY16 and PH17, and XY16 and PH18 also showed a significant correlation at $P<$ 0.05 and $P<0.005$ (Fig. 1). The equation for the broad sense heritability $\left(H^{2}\right)$ calculation was $H^{2}=\mathrm{V}_{\mathrm{G}} /\left(\mathrm{V}_{\mathrm{G}}+\right.$ $\left.V_{E}\right), V_{G}$ and $V_{E}$ represent genetic variance and environmental variance, respectively. The traits datasets we collected has 181 lines and they were evaluated in 3 environments and 3 replications in 3 years, the genetic variance and $H^{2}$ were estimated by using "mmer" function in sommer $\mathrm{R}$ packages executed liner mixed models $[53,54]$. The year-to-year variance for LTP was and 


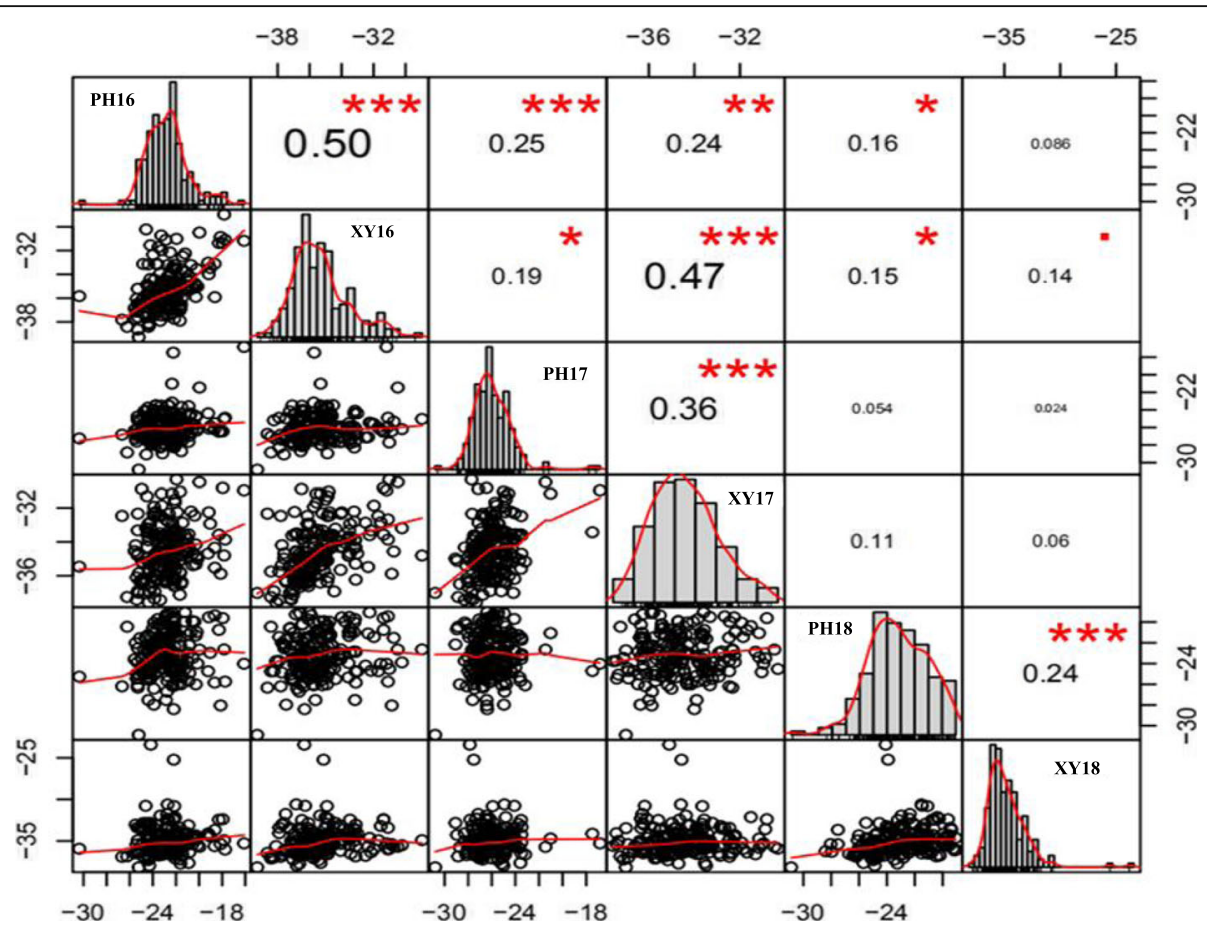

Fig. 1 Correlations analysis of phenotypic data between different years. "**", "*** and "***" represent the significant level at $P<0.01,0.005$ and 0.001

LTX were 3.08 and 2.57. $H^{2}$ of LTP was 0.42 , and the $H^{2}$ of LTX was 0.56.

\section{Raw data analysis and SNP marker development}

In total, $322.68 \mathrm{~Gb}$ of data were obtained from the two parents and 181 hybrid offspring based on RAD sequencing; 1,010,172,055 clean reads were obtained by filtering the original data, among which 46,762,423 were from the maternal parent 'Cabernet sauvignon' and 36,408, 094 were from paternal parent 'Zuoyouhong'. Clean read number distributions of the 181 hybrid offspring shown in Additional file 2: Fig. S1. In the filtered data, the GC content and Q30 of the maternal parent were 36.44 and 91.64\%, paternal parent were 37.97 and $93.80 \%$. Sequencing depth can affect accuracy of mutation detection. In this study, the average sequencing depths of 'Cabernet sauvignon' and 'Zuoyouhong' were 24.01 and 19.40, respectively, the sequencing depth distribution of the hybrid offspring is shown in Additional file 2: Fig. S1.

In total of 56,779 markers were called in this study, among them, 6971 were monomorphic marker. A Chisquare test $(p<0.01)$ was conducted for these polymorphism markers and 14,927 distorted markers were then removed. After standard filtering, 28,051 markers were obtained and used to construct genetic linkage maps (Table 1). Of the 28,051 SNP markers, 26,106 were homozygous for one parent and heterozygous for the other $(15,505$ for $\mathrm{lm} \times \mathrm{ll}$ and 10,601for $\mathrm{nn} \times \mathrm{np})$, constituting 93.1\% of all selected SNP markers. The remaining 1945 markers were constituted by three different types, including ab $\times \mathrm{cd}(4)$, ef $\times$ eg (85), and hk $\times$ hk (1856) (Fig. 2), these markers were contained in both the female and male maps.

\section{Genetic linkage map construction}

The retained 28,051 markers were assigned to 19 linkage groups, finally, 25,917 were anchored on the genetic map at Logarithm of odds (LOD) score thresholds $\geq 7$ (Table 2, Additional file 3: Data S2) and the Mendelian segregation and depth of each marker is shown in Additional file 4: Data S3. The Kosambi function was used to estimate genetic map distances. For 'Cabernet sauvignon', 16,076 SNP makers were distributed in 19 linkage groups with a total map length of $1548.11 \mathrm{cM}$. Among the 19 linkage maps, the shortest was LG11 with a genetic length of $53.72 \mathrm{cM}$ and the longest was LG14 with a genetic length of $120.65 \mathrm{cM}$. Marker number in each linkage group ranged from 439 to 1715 , LG2 contained

Table 1 Number statistics analysis of different marker category

\begin{tabular}{ll}
\hline Category & Number \\
\hline Original number of called markers & 56,779 \\
Monomorphic marker & 6971 \\
Distorted marker & 14,927 \\
Markers on the genetic map & 28,051 \\
\hline
\end{tabular}




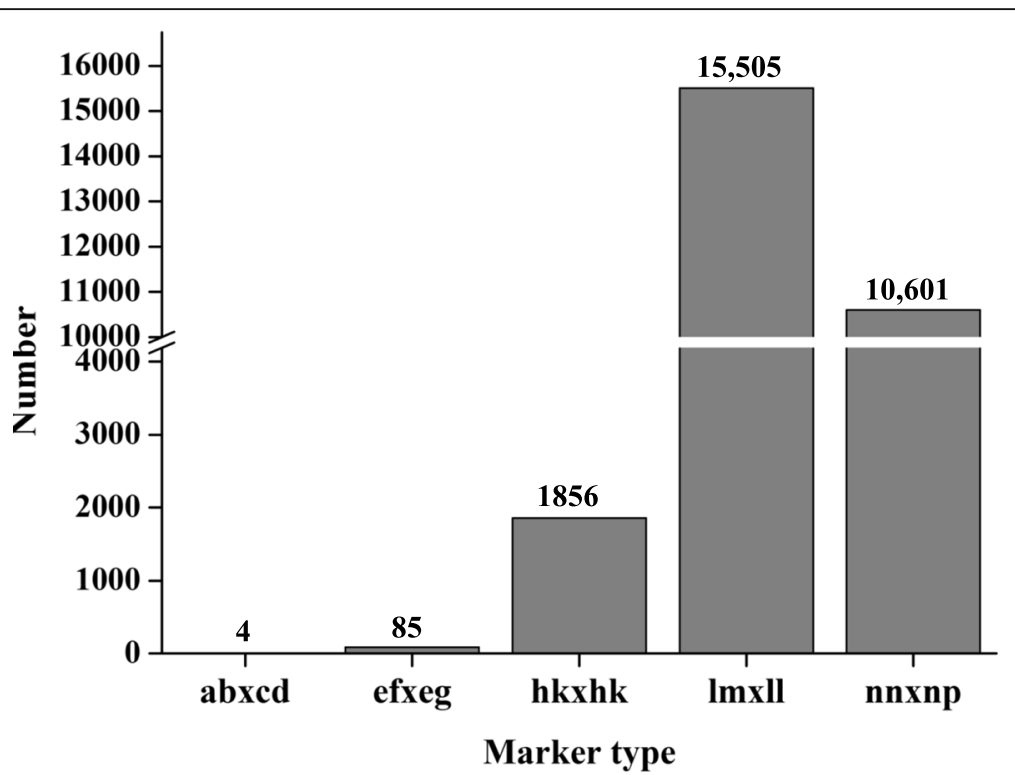

Fig. 2 Number of different genotype markers. Im $\times \|$ represent the markers used for female map construction and the order was malexfemale, $\mathrm{nn} \times \mathrm{np}$ represent the markers used for male map construction and the order was femalexmale, abxcd, ef $\times$ eg and hk $\times$ hk represent the markers contained by both of the parents

Table 2 Marker distribution and total genetic length of 19 linkage groups

\begin{tabular}{|c|c|c|c|c|c|c|}
\hline \multirow{2}{*}{$\begin{array}{l}\text { Linkage } \\
\text { group } \\
\text { ID }\end{array}$} & \multicolumn{3}{|c|}{ Maker Number } & \multicolumn{3}{|c|}{ Genetic distance (cM) } \\
\hline & Female Map & Male map & Integrated map & Female Map & Male map & Integrated map \\
\hline$\overline{L G 1}$ & 775 & 477 & 1209 & 98.43 & 99.95 & 99.20 \\
\hline LG2 & 439 & 570 & 985 & 70.88 & 84.84 & 78.97 \\
\hline LG3 & 466 & 444 & 896 & 81.29 & 69.94 & 77.63 \\
\hline LG4 & 868 & 642 & 1415 & 78.29 & 137.36 & 109.78 \\
\hline LG5 & 776 & 871 & 1585 & 82.45 & 89.30 & 86.71 \\
\hline LG6 & 668 & 587 & 1117 & 58.01 & 79.03 & 69.36 \\
\hline LG7 & 1151 & 524 & 1584 & 91.45 & 103.33 & 106.52 \\
\hline LG8 & 571 & 411 & 955 & 86.19 & 102.77 & 154.17 \\
\hline LG9 & 644 & 567 & 1173 & 80.04 & 79.25 & 79.91 \\
\hline LG10 & 743 & 452 & 1065 & 62.59 & 52.58 & 75.82 \\
\hline LG11 & 764 & 679 & 1288 & 53.72 & 72.39 & 64.8 \\
\hline LG12 & 1281 & 604 & 1728 & 97.75 & 91.40 & 96.82 \\
\hline LG13 & 1357 & 515 & 1707 & 89.59 & 100.60 & 95.37 \\
\hline LG14 & 1715 & 866 & 2381 & 120.65 & 157.51 & 147.20 \\
\hline LG15 & 889 & 637 & 1362 & 75.26 & 102.39 & 88.83 \\
\hline LG16 & 633 & 643 & 1251 & 72.58 & 81.49 & 77.54 \\
\hline LG17 & 668 & 690 & 1173 & 58.39 & 63.37 & 61.07 \\
\hline LG18 & 822 & 799 & 1602 & 108.49 & 135.81 & 124.11 \\
\hline LG19 & 846 & 665 & 1441 & 82.06 & 87.9 & 86.67 \\
\hline Total & 16,076 & 11,643 & 25,917 & 1548.11 & 1791.21 & 1780.48 \\
\hline
\end{tabular}


the smallest number of markers and LG14 contained the largest number of markers (Table 2, Additional file 5: Data S4). In our study, many markers in the female map were anchored in the same genetic position, and we conducted analysis to determine these markers by generating bin markers. Each bin marker represents a unique position. For the female map, 2384 bin markers were obtained (Additional file 6: Data S5). The average genetic distance of adjacent bin markers in the 19 linkage groups was $0.65 \mathrm{cM}$. The longest average genetic distance of an adjacent marker was observed in LG10 with a length of $1.20 \mathrm{cM}$, whereas the shortest were found in LG13 with a length of $0.5 \mathrm{cM}$. The largest gap for this map was contained in LG1 with the distance $9.73 \mathrm{cM}$. Besides LG1, LG2, LG3, LG5, LG8, and LG10, the percentage of Gap $\leq 5 \mathrm{cM}$ (gap less than or equal to $5 \mathrm{cM}$ ) checked in the other linkage groups reached 100\% (Table 3, Additional file 7: Fig. S2).

A total of 11,643 SNP markers were anchored into 19 linkage groups of the paternal parent with a total genetic length of $1791.21 \mathrm{cM}$. The genetic length of each linkage group ranged from 52.58 to $157.51 \mathrm{cM}$. The longest was LG14 and shortest was LG10. Marker number in each linkage group ranged from 411 to 871 ; LG8 contains the smallest number and LG5 contained the largest number
(Table 2, Additional file 5: Data S4). Finally, a total of 2330 bin markers were generated (Additional file 6: Data S5), and the average genetic distance between adjacent markers in the 19 linkage groups was $0.77 \mathrm{cM}$. The longest one was LG7 with genetic lengths of $1.04 \mathrm{cM}$, and the shortest ones were LG10 and LG17 with genetic lengths of $0.60 \mathrm{cM}$. For the male map, nearly half of the linkage groups contained the regions of Gap $>5 \mathrm{cM}$, and the largest gap for this map was contained in LG19 with the distance $28.19 \mathrm{cM}$ (Table 3, Additional file 8: Fig. S3).

The integrated map contained 25,917 SNP markers with a total genetic length of $1780.48 \mathrm{cM}$. The shortest linkage group was LG17 and longest was LG8 with genetic lengths of 61.07 and $154.17 \mathrm{cM}$. Among the 19 linkage groups, LG14 contained the largest SNP number of 2381 and LG3 contained the smallest number of 896 (Table 2, Additional file 5: Data S4). A total of 4383 bin markers were generated (Additional file 6: Data S5), and the average genetic distance between adjacent bin markers in the 19 linkage groups was $0.41 \mathrm{cM}$. The shortest genetic distance was found in LG12 with a value of $0.31 \mathrm{cM}$, whereas the longest was found in LG8 with a value of $0.70 \mathrm{cM}$. Additionally, 8 Gap $>5 \mathrm{cM}$ regions were found in LG2, LG7, LG8, LG10, and LG14, the largest gap was contained in LG10 with $11.3 \mathrm{cM}$ (Table 3 and Fig. 3).

Table 3 Genetic distance of adjacent markers in 19 linkage groups

\begin{tabular}{|c|c|c|c|c|c|c|}
\hline \multirow{2}{*}{$\begin{array}{l}\text { Linkage } \\
\text { group } \\
\text { ID }\end{array}$} & \multicolumn{3}{|c|}{ Average genetic distance $(\mathrm{cM})$} & \multicolumn{3}{|c|}{ Percentage of Gap $\leq 5$ cM(Max Gap) } \\
\hline & Female Map & Male map & Integrated map & Female Map & Male map & Integrated map \\
\hline$\overline{\mathrm{LG} 1}$ & 0.72 & 0.85 & 0.41 & $99.87 \%(9.73)$ & $99.58 \%(8.40)$ & $100.00 \%(2.97)$ \\
\hline LG2 & 0.84 & 0.81 & 0.44 & $99.77 \%(5.24)$ & $99.82 \%(7.22)$ & $99.90 \%(5.06)$ \\
\hline LG3 & 0.82 & 0.93 & 0.46 & $99.57 \%(8.32)$ & $99.55 \%(7.11)$ & $100.00 \%(2.93)$ \\
\hline LG4 & 0.67 & 0.95 & 0.46 & $100.00 \%(3.43)$ & $99.69 \%(5.67)$ & $100.00 \%(3.07)$ \\
\hline LG5 & 0.70 & 0.63 & 0.36 & $99.87 \%(5.85)$ & $100.00 \%(3.43)$ & $100.00 \%(1.94)$ \\
\hline LG6 & 0.60 & 0.79 & 0.37 & $100.00 \%(2.26)$ & $100.00 \%(4.03)$ & $100.00 \%(2.14)$ \\
\hline LG7 & 0.62 & 1.04 & 0.48 & $100.00 \%(2.72)$ & $99.43 \%(15.22)$ & $99.94 \%(9.73)$ \\
\hline LG8 & 0.75 & 0.88 & 0.70 & $99.65 \%(8.40)$ & $99.51 \%(11.01)$ & $99.69 \%(9.49)$ \\
\hline LG9 & 0.68 & 0.71 & 0.37 & $100.00 \%(2.76)$ & $100.00 \%(3.43)$ & $100.00 \%(1.77)$ \\
\hline LG10 & 1.20 & 0.60 & 0.57 & $99.60 \%(10.30)$ & $100.00 \%(2.84)$ & $99.72 \%(11.3)$ \\
\hline LG11 & 0.65 & 0.78 & 0.39 & $100.00 \%(4.03)$ & $99.85 \%(17.72)$ & $100.00 \%(4.21)$ \\
\hline LG12 & 0.52 & 0.66 & 0.31 & $100.00 \%(1.69)$ & $100.00 \%(3.43)$ & $100.00 \%(1.69)$ \\
\hline LG13 & 0.50 & 0.94 & 0.35 & $100.00 \%(2.26)$ & $99.81 \%(14.66)$ & $100.00 \%(3.56)$ \\
\hline LG14 & 0.56 & 0.77 & 0.39 & $100.00 \%(2.26)$ & $99.88 \%(10.03)$ & $99.96 \%(9.22)$ \\
\hline LG15 & 0.55 & 0.65 & 0.33 & $100.00 \%(2.26)$ & $100.00 \%(3.43)$ & $100.00 \%(1.68)$ \\
\hline LG16 & 0.59 & 0.62 & 0.32 & $100.00 \%(4.03)$ & $100.00 \%(2.84)$ & $100.00 \%(2.20)$ \\
\hline LG17 & 0.61 & 0.60 & 0.36 & $100.00 \%(4.03)$ & $100.00 \%(2.84)$ & $100.00 \%(2.01)$ \\
\hline LG18 & 0.74 & 0.78 & 0.40 & $100.00 \%(3.43)$ & $99.87 \%(7.25)$ & $100.00 \%(2.75)$ \\
\hline LG19 & 0.68 & 0.87 & 0.41 & $100.00 \%(2.84)$ & $99.85 \%(28.19)$ & $100.00 \%(3.15)$ \\
\hline Average & 0.68 & 0.78 & 0.41 & & & \\
\hline
\end{tabular}




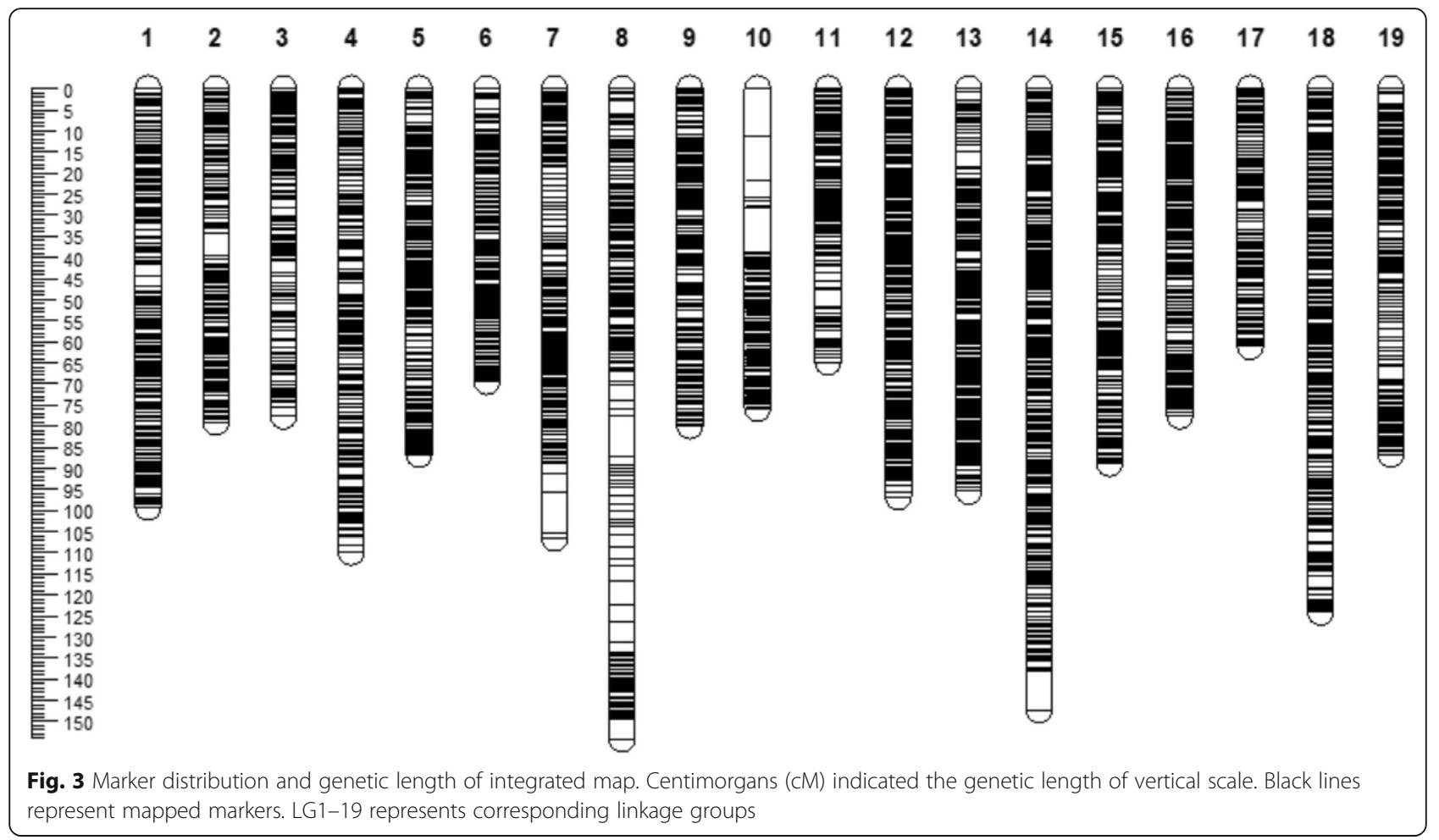

QTL mapping and candidate genes involved in grapevine cold hardiness

In this study, we conducted QTL mapping for the LTP and LTX during 3 years based on the integrated map. The outliers of the phenotypic value including line1 in PH16, line 85 in XY16, line 139, 149, 156 and 168 in PH17 and line 59 and 121 in XY18 were removed prior to QTL mapping. For the LTP, two major QTLs were identified on LG3 and LG15, corresponding to the trait of PH16. The confidence intervals of these two QTLs were $17.11 \mathrm{cM}-30.73 \mathrm{cM}$ and $50.56 \mathrm{cM}-64.66 \mathrm{cM}$, Each QTL explained $8.47-8.52 \%$ of the phenotypic variation $\left(R^{2}\right)$ (Table 4 and Fig. 4). For the LTX, two QTLs were identified on LG 2 in the year of 2016 and 2017. The confidence intervals of these two QTLs were $49.13 \mathrm{cM}-$ $75.07 \mathrm{cM}$ and $57.29 \mathrm{cM}-70.99 \mathrm{cM}$. The phenotypic variation they explained was 8.34 and $11.73 \%$, respectively (Table 5 and Fig. 4).

We tried to calculated the best linear unbiased predictor (BLUP) value for each individual line across all environments using the mixed linear model in the $R$ package "lme4" and then the BLUP values were used for QTL mapping based on integrated map (Additional file 9: Data S6). A major QTL related to LTP was identified on LG15, corresponding to the confidence interval of 52.42 cM-68.94 cM, explained $7.33 \%$ of the total phenotypic variation (Table 4 and Fig. 4); QTL related to LTX was identified on LG2, corresponding to the confidence interval of $59.32 \mathrm{cM}-74.88 \mathrm{cM}$, explained $9.38 \%$ of the total phenotypic variation (Table 5 and Fig. 4).

Confidence interval of PH16 in LG3 and LG15corresponding to the region of Chr3: 6669508-Chr3:7621469 and chr15:15072086-chr15:16909415 on physical map; the QTL region of transformed LTP values corresponding to chr15: 15252067- chr15:17430019 on physical map (Table 4). QTL confidence intervals of XY16 and XY17 were both located on LG2, corresponding to the physical map region of Chr2: 6750680-Chr2:17798856 and chr2:8147811-chr2:16574359; the QTL region of transformed LTX values corresponding to chr2:8632628-chr2:17864890 on physical map (Table 5).

A stable QTL overlapping region was discovered on LG15 between PH16 and the transformed BLUP LTP

Table 4 QTL mapping for lethal temperature of phloem based on integrated map

\begin{tabular}{lllllll}
\hline Traits & LG & Peak LOD & Co-segregated marker & Peak Location (cM) & $R^{2}(\%)$ & Confidence interval (cM) \\
\hline PH16 & 3 & 3.21 & chr3_7,621,469 & 17.11 & 8.47 & $17.11-30.73$ \\
PH16 & 15 & 3.23 & chr15_15,252,067 & 52.42 & 8.52 & $50.56-64.66$ \\
BLUP & 15 & 3.87 & chr15_16601112 & 61.95 & 7.33 & $52.42-68.94$
\end{tabular}

$R^{2}$ represents the individual contribution of one QTL to the variation in cold hardiness 


\section{QTL Mapping}

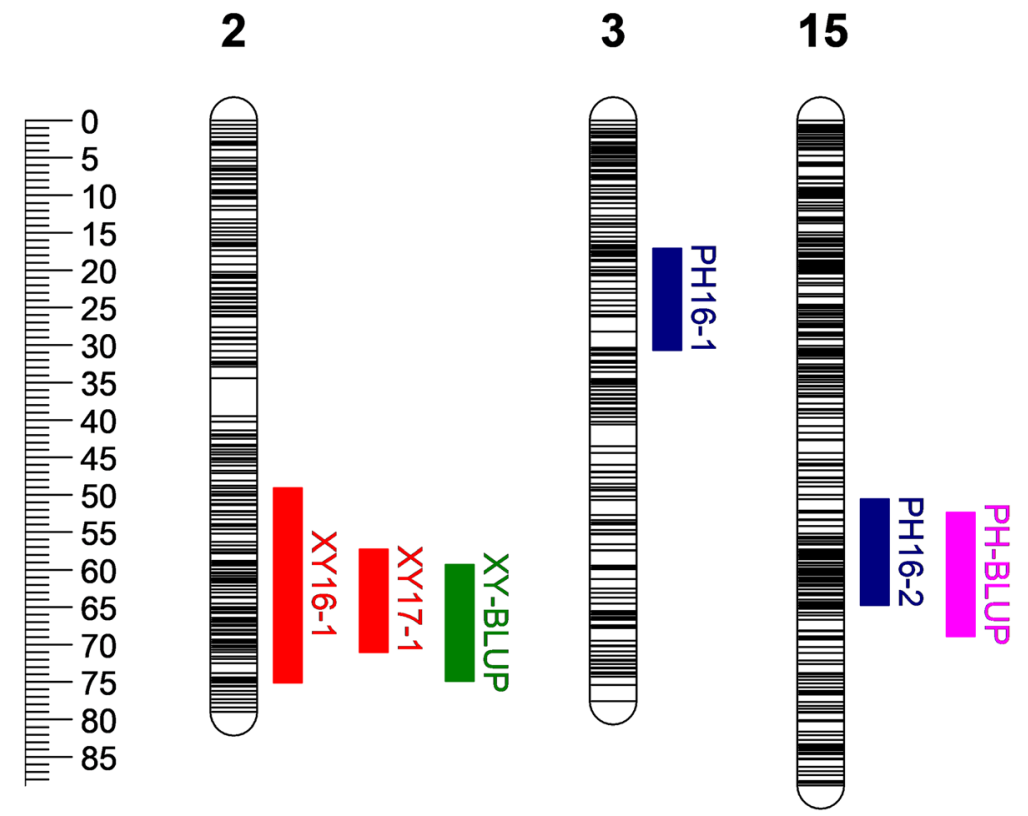

Fig. 4 QTL mapping of grapevine cane cold hardiness. Blue color represents the confidence interval of grapevine phloem; red color represents the confidence interval of grapevine xylem; pink color represent the confidence interval of QTL mapping based on phloem BLUP values; green color represent the confidence interval of QTL mapping based on xylem BLUP values

values (Fig. 4), covering a confidence interval $52.42 \mathrm{cM}-$ $68.94 \mathrm{cM}$ with flanked markers chr15_15,252,067 and chr15_16,909,415 corresponding to chr15:15252067chr15:16909415 on physical map; For LTX, a stable QTL overlapping region was discovered on LG2 between XY16, XY17 and the transformed BLUP LTX values (Fig. 4), covering a confidence interval $59.32 \mathrm{cM}-70.99$ cM with flanked markers chr2_8,632,628 and chr2_16, 574,359, corresponding to chr2: 8632628-chr2: 16574359 on physical map.

A total of 458 genes were selected based on these two overlapping regions on LG2 and LG15 according to their functional annotation registered in the database (Additional file 10: Data S7) and then the gene ontology (GO) enrichment analysis was performed for genes. Finally, 215 genes were classified into 10 significant GO terms (Additional file 11: Fig. S4). Four genes which involved in the GO term "response to cold" (GO: 0009409) were selected as the candidate cold hardiness resistance genes (Table 6).

\section{Discussion}

Cold hardiness phenotypic determination

In our study, the grapevine cultivar 'Zuoyouhong' was came from the cross of $V$. vinifera $\mathrm{L}$. and $V$. amurensis Rupr., and 'Cabernet sauvignon' belongs to $V$. vinifera $\mathrm{L}$., crossing of these two cultivars yields a large number of offspring, indicating good performance of interspecific hybridization affinity. Based on our observation, the cold hardiness value of the offspring showed extensive continuous variation and provides an important population material for cold hardiness QTL mapping. Besides that, we also conducted the filed observation of many grapevine cultivars from different species for many years. For grapevine cultivars which belong to $V$. vinifera $\mathrm{L}$., the average value of LTP and LTX were $-21.10^{\circ} \mathrm{C}$ and $-31.20^{\circ} \mathrm{C}$; grapevine cultivars which belong to $V$. labrusca $\mathrm{L}$. were $-25.20^{\circ} \mathrm{C}$ and $-34.96^{\circ} \mathrm{C}$; grapevine cultivars which belong to $V$. amurensis Rupr. were $-32.85^{\circ} \mathrm{C}$ and $-39.68^{\circ} \mathrm{C}$; Cultivars which came from the interspecies cross of $V$. vinifera $\times V$. amurensis were $26.11{ }^{\circ} \mathrm{C}$ and $-36.7^{\circ} \mathrm{C}$; cultivars which came from $V$.

Table 5 QTL mapping for lethal temperature of xylem based on integrated map

\begin{tabular}{lllllll}
\hline Traits & LG & Peak LOD & Co-segregated marker & Peak Location (cM) & $R^{2}(\%)$ & Confidence interval (cM) \\
\hline XY16 & 2 & 3.41 & chr2_8,632,628 & 59.32 & 8.34 & $49.13-75.07$ \\
XY17 & 2 & 4.91 & chr2_8,632,628 & 59.32 & 11.73 & $57.29-70.99$ \\
BLUP & 2 & 4.61 & chr2_8,632,628 & 59.32 & 9.38 & $59.32-74.88$ \\
\hline
\end{tabular}

$R^{2}$ represents the individual contribution of one QTL to the variation in cold hardiness 
Table 6 Candidate genes related to cane cold hardiness resistance

\begin{tabular}{lll}
\hline Gene ID & Physical position & Functional annotation \\
\hline VIT_02s0033g01120 & chr02:16403096-16,408,471 & Dehydration-responsive protein \\
VIT_15s0048g01980 & chr15:16098098-16,109,673 & COP9 signalosome complex subunit 1 \\
VIT_15s0048g02410 & chr15:16591114-16,601,303 & Myb CCA1 (circadian clock associated 1) \\
VIT_15s0048g02700 & chr15:16831342-16,836,139 & RNA recognition motif (RRM)-containing protein
\end{tabular}

vinifera $\times$ V. labrusca were $-22.24{ }^{\circ} \mathrm{C}$ and $-32.86^{\circ} \mathrm{C}$. Some researches indicated that $V$. amurensis was the most responsive species to temperature fluctuations and showed strong cold hardiness $[55,56]$, this was the same to our observation. In this study, cold hardiness was identified by low-temperature exotherm method, which shows much higher accuracy than traditional electrical conductivity method and has been widely utilized in apple, red maple, walnut, grape, and other woody plants [55-61].

\section{Genetic map evaluation}

In recent years, numerous genetic maps have been constructed for grape by using SNP markers based on next- generation sequencing technology. The sequencing strategies included genotyping by sequencing (GBS), specific locus amplified fragment sequencing (SLAF), and restriction site-associated DNA sequencing (RAD), increasing the number of markers from more than one thousand to tens of thousands. This greatly narrowed the average genetic inter-marker distance of linkage maps from $1.32 \mathrm{cM}$ to $0.05 \mathrm{cM}[3,6,11,12,16,40]$. In this study, the hybrid offspring number was 181 and we achieved $322.68 \mathrm{~Gb}$ sequencing data. SNP marker detection and screening revealed 16,076, 11,643, and 25,917 SNP markers anchored in female, male, and integrated maps with average genetic distances of adjacent makers

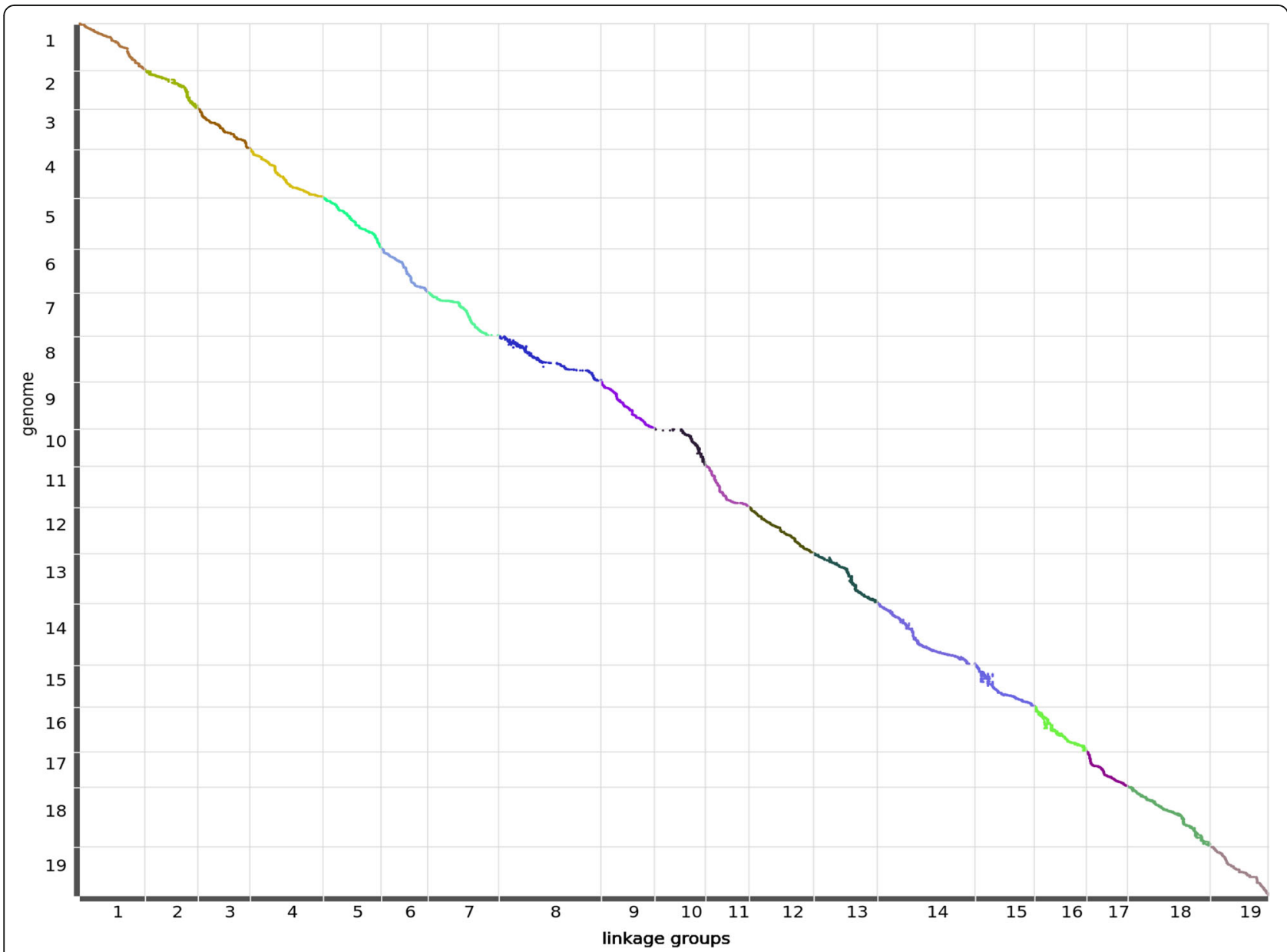

Fig. 5 Collinearity analysis between integrated map and referenced grapevine genome PN40024. X-axis represents the genetic length of each linkage group; Y-axis represents the physical length of each linkage group 
of $0.65 \mathrm{cM}, 0.77 \mathrm{cM}$, and $0.41 \mathrm{cM}$, respectively. Based on our integrated map, many markers in close physical proximity were co-segregated in a unique distance locus due to lack of recombination, for example, in LG1, marker chr1_19616688, chr1_19602344, chr1_19606836, chr1_19634588, these four markers were located at the same genetic position in close physical proximity. Considering the population size used in our study, it is necessary for us to use more sequencing individuals in the future and recalculate the location of these markers for further increase the quality of our linkage map.

Collinearity is an important indicator of the quality of a linkage map and is based on the marker order in linkage maps compared to the locations on the reference grapevine genome (Fig. 5). In this study, the Spearman coefficient of most linkage groups was higher than 0.99 (Additional file 12: Data S8), the marker order in the linkage map of our study showed good collinearity performance compared to the physical map, indicating a higher accuracy of genetic recombination rate. This was also observed for the haplotype and heat maps (Additional file 13: Fig. S5 and Additional file 14: Fig. S6). The linkage map in our study also showed good marker densities across the chromosome (Fig. 6). Some larger gaps were observed in LG7, LG8, LG10, and LG14. Previous studies have showed that unlinked scaffolds which account for $9 \%$ of the grapevine reference sequence remains unanchored to chromosome and they were called Unknown chromosome [62]. Tello et al. 2019 found that 76 SNP markers from Unknown chromosomes were positioned in eight LGs [13]. While in our study, the "Unknown" chromosome markers were not called. So, markers from Unknown chromosomes may be the reason for larger gaps, because they might be positioned in these regions. While in our study, no unknown chromosome markers were called. The absence of marker polymorphism in these regions, heterozygosity of the parents and missing data can also limit the marker detection and yield large gaps [17, 63-65]. Zhu et al., 2018 also found that long physical distance can also related to large gaps [12]. In our study, flanking markers chr10_138837, chr10_714452,

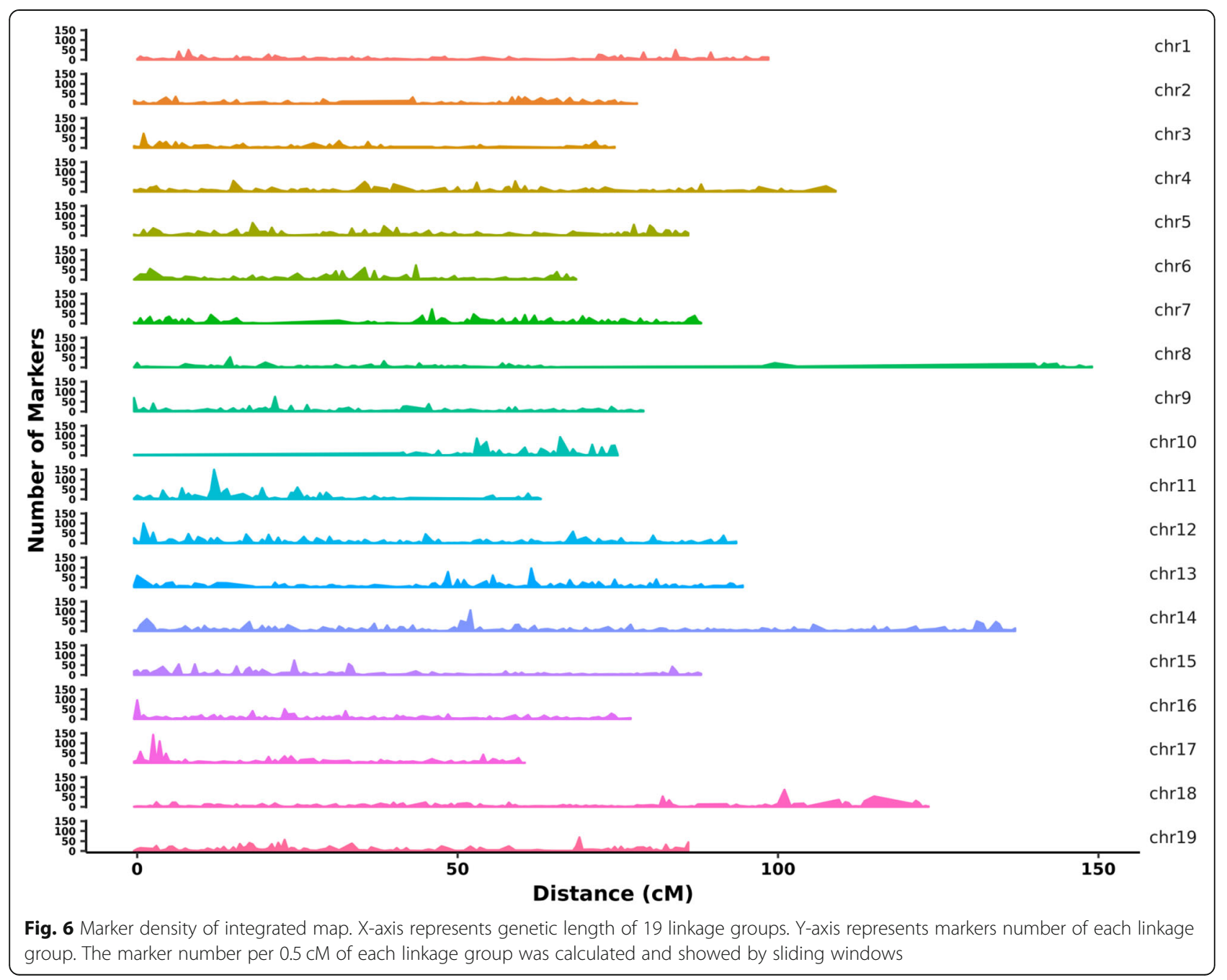


which located on genetic distance $0.0 \mathrm{cM}$ and $10.3 \mathrm{cM}$ in female map LG10, they were physically locatted 13 and 70 $\mathrm{kb}$ apart in physical map.

\section{QTL mapping and candidate genes}

The application of molecular markers has greatly promoted the process of grape breeding, but obtaining stable genetic QTLs and applying them in molecularassisted breeding remains difficult. Based on the phenotypic data of cane cold hardiness and constructed genetic map, we totally found 6 QTLs on integrated map. The explained phenotypic variation was between 7.33 and $11.73 \%$. Overlap regions of QTLs related to LTP and LTX were detected in LG2 and LG15 on the integrated map. The lower explained phenotypic variation in this study was similar to other quantitative traits of grapevine, such as cluster number, single cluster weight, and single berry weight $[46,66]$. This may because the metabolic regulatory pathways related to these quantitative traits are complex with large numbers of QTLs controlling a certain trait [51]. According to Beavis effect, when the sample size was small, the explained phenotypic variation would be greatly inflated and the larger the sample size, the smaller of the QTL effect and the closer to the true value [67-69].

According to the previous studies, candidate genes involved in the stable QTL regions may play important role in grapevine resistance to cold hardiness. Dehydration-responsive protein contains cis-acting element DRE (dehydration-responsive element), in Arabidopsis, it can be regulated by dehydration-responsive element binding protein through abscisic acid (ABA)-independent pathway under cold and dehydration environment [70]. The COP9 signalosome (CSN) is a multiprotein complex that is conserved in most eukaryotes. Cold stress rapidly induces the expression of a series of cold-regulated (COR) genes in Arabidopsis and the expression of COR genes requires the activities of CSN [71, 72]. It has been reported that a number of RNA-binding proteins from a cyanobacterium comprise a single RRM module and are highly expressed in response to cold stress [73, 74]. A MYB-like gene $\mathrm{VaA}$ QUILO from amur grape ( $V$. amurensis Rupr.) was induced by cold, overexpression results of this gene in transgenic Arabidopsis and in Amur grape calli showed significantly tolerance to cold [75]. The identification of the most relevant genes would provide some references for understanding the molecular mechanisms operating in grapevine cold hardiness. However, these genes were speculative and functional validations would be necessary to understand the molecular mechanism in the future. Finally, this study was first to localize two major reproducible QTLs and can provide important reference for grapevine cold hardiness breeding.

\section{Conclusion}

Compared to previously constructed genetic maps, the SNP marker number in the in this study was much higher and we obtained a high-density and high-quality genetic map, providing a foundation for fine QTL mapping of important agronomic traits of grapevine. We first identified six QTLs associated with grape cane phloem and xylem cold hardiness. Based on the preliminary QTL mapping results, we detected four candidate genes that may be involved in regulating cold hardiness in grapevine. Until now, there are no reports of grape cold hardiness QTL mapping, thus, these results will provide a reference for future studies, and we will continue to conduct grapevine cold hardiness research based on our results in combination with other biological technologies such as transcriptomics, proteomics, and metabolomics approaches. The results in our study will provide an important theoretical basis for grapevine cold hardiness breeding.

\section{Methods \\ Plant material}

In this study, the grape cultivar 'Cabernet sauvignon' ( $V$. vinifera $\mathrm{L}$.) and 'Zuoyouhong' ( $V$. vinifera $\times V$. amurensis) was planted in the vineyard of Shenyang Agricultural

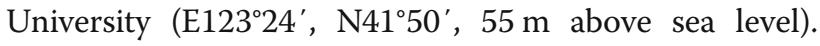
Crossbreeding work was conducted based on the maternal parent 'Cabernet sauvignon' and paternal parent 'Zuoyouhong' in May 2013 and the seeds were collected in October 2013. The collected seeds were stored under a stratification method between October 2013 and February 2014 and sown in the greenhouse of the same vineyard in March 2014. In total, 680 individuals were harvested and 181 seedlings and the two parents planted in green houses were used as the mapping population.

\section{Cane phloem and xylem cold hardiness identification}

The low-temperature exotherm method was used to identify cold hardiness. Annual grapevine canes were collected in midwinter of 2016, 2017 and 2018 for 181 genotypes and two parents and then they were kept in cold room with $4{ }^{\circ} \mathrm{C}$. After that, the cold hardiness detection was conducted. Approximately $30-\mathrm{mm}$ long cylindrical sections of cane were cut from the internode area between nodes four and eight, and two such cane pieces were each placed directly on thermoelectric modules (TEM) that can convert the thermal signals to voltage $(\mathrm{mV})$ outputs. Three replicates per genotype were detected. To ensure the adequate contact between the tissues and TEM, foam insulation pads were used and placed on the top of can pieces in each well and then covered with a chamber lid. A total of three chambers (containing 27 TEMS) were stacked in a programmed cooling refrigerator (Anke Environmental Testing 
Equipment Company, Hefei, China) and the program was as follows: temperature was decreased from room temperature to $4{ }^{\circ} \mathrm{C}$ held at this temperature for $1 \mathrm{~h}$; the temperature was decreased from $4{ }^{\circ} \mathrm{C}$ to $-40^{\circ} \mathrm{C}$ at a rate of $4{ }^{\circ} \mathrm{C} / \mathrm{h}$, and then held for $1 \mathrm{~h}$ and return to room temperature over $1 \mathrm{~h}$. The ultra-low temperature exothermic process of plant cells during the stable temperature drop was recorded in every $15 \mathrm{~s}$ with a data acquisition and processing system (Beijing Huayi Ruike Technology, Beijing, China). For canes, the lethal temperatures of phloem (LTP) were determined by assuming the first range (from site A to site B) of exotherms below $-10^{\circ} \mathrm{C}$. As the temperature continued to decline, a second range of exotherms (from site $\mathrm{B}$ to site $\mathrm{C}$ ) indicated the xylem parenchyma death (LTX) (Fig. 7). In this study, the temperature values at site $\mathrm{B}$ and $\mathrm{C}$ were recognised as the lethal temperature of phloem and xylem, and these values were used for grapevine cold hardiness evaluation.

\section{Library construction for sequencing}

Young and healthy leaves were collected from the two parents and 181 individuals. The leaves were frozen in liquid nitrogen and stored at $-80^{\circ} \mathrm{C}$. A modified CTAB method was used to extract genomic DNA [76]. A NanoDrop 2000 spectrophotometer (Thermo Fisher Scientific, Waltham, MA, USA) was used to evaluate DNA concentration and quality. The qualified DNA of each individual was digested by TaqI restriction endonuclease (New England Biolabs, Ipswich, MA, USA) and then barcoded P1 adapters were ligated to the TaqI restriction site for each individual. Thereafter, samples were pooled in proportional amounts for shearing to an average size of $500 \mathrm{bp}$ with a Bioruptor (Diagenode, Liège, Belgium). Sequencing libraries were constructed randomly with a total of 24 samples per library. Fragment sizes ranging from 300 to 500 base pairs were extracted by $2 \%$ agarose gel electrophoresis and then ligated with the P2 adapter containing unique Illumina barcodes (San Diego, CA, USA). The constructed library was amplified by PCR with Phusion high-fidelity DNA polymerase (New England Biolabs) and the running conditions were: $98^{\circ} \mathrm{C}$ for $2 \mathrm{~min}$, followed by 13 cycles at $98^{\circ} \mathrm{C}$ for $30 \mathrm{~s}, 60^{\circ} \mathrm{C}$ for $30 \mathrm{~s}$, and $72{ }^{\circ} \mathrm{C}$ for $15 \mathrm{~s}$, and a final extension at $72^{\circ} \mathrm{C}$ for $5 \mathrm{~min}$. Finally, the samples of each individual were sequenced on an Illumina HiSeq ${ }^{\text {mi }}$ platform with the Illumina PE150 strategy (paired-ends). The clean read data size of the two parents was $10 \mathrm{~Gb}$ and the data size of each offspring were $1 \mathrm{~Gb}(\mathrm{Q} 30>80 \%)$.

\section{SNP marker development and genetic linkage map construction}

The original image obtained by Illumina HiSeqTM sequencing was converted into sequence format by base calling, and the obtained original sequence was stored in FASTQ format. The joints were removed from the obtained original data, filtration was carried out to remove low-quality data, and clean reads for subsequent test analysis were obtained. High-quality filtered data were mapped to the Vitis vinifera PN40024 reference genome

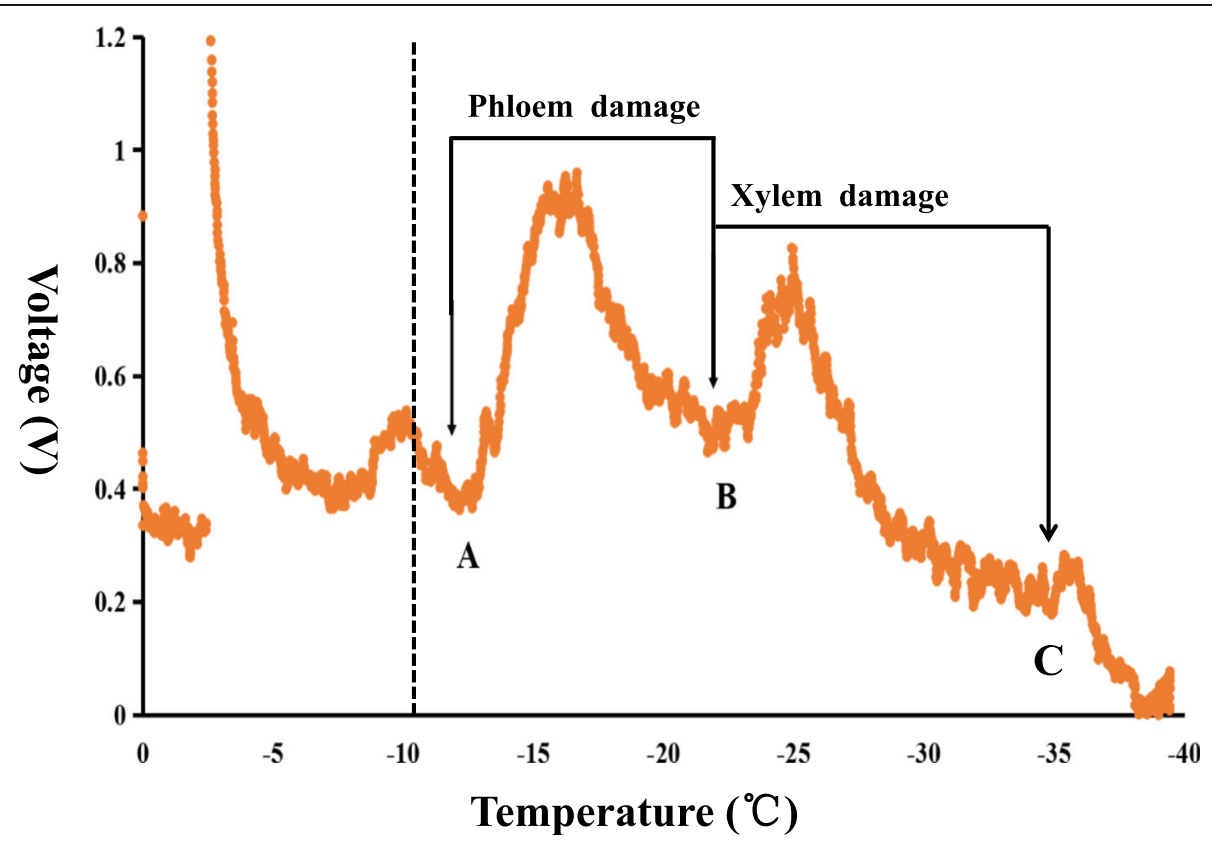

Fig. 7 The lethal temperatures of phloem and xylem parenchyma death detected by using low-temperature exotherm method. Site B represents the lethal temperature of phloem, site $C$ represents the lethal temperature of xylem 
(https://plants.ensembl.org/Vitis_vinifera/Info/Index) by using BWA software and then the BWA file was obtained [77]. Subsequently, the Best Practices pipeline of GATK software was used to calibrate the BWA file and develop SNP markers [78]. Based on basic genetic principles, all SNPS were screened to obtain molecular markers that met the requirements of genetic map construction. The filter standards were as follows: sequencing depths of the two parents and progeny were more than $10 \times$; at least of one of the two parents possessed a heterozygous genotype; the segregation ratio of progeny was tested by Chi-square test $(p<0.05)$; the genotype missing rate was 0 . There are five segregation types of $\mathrm{CP}$ populations $(\mathrm{lm} \times \mathrm{ll}, \mathrm{nn} \times \mathrm{np}$, hk $\times \mathrm{hk}$, ef $\times \mathrm{eg}$, and $\mathrm{ab}$ $\times \mathrm{cd}$ ), and they were genotyped into three types: ' $\mathrm{lm} \times \mathrm{ll}$ ' represents markers with first parent heterozygous and second parent homozygous; ' $n n \times n p$ ' represents markers with the first parent homozygous and the second parent heterozygous; ' $h \mathrm{k} \times \mathrm{hk}$ ' represents markers with both parents heterozygous, these three segregation types were used for constructing male, female, and integrated linkage map. Finally, JoinMap 5.0 software was used to construct the genetic linkage map, and the minimum logarithm of odds (LOD) score of 7.0 was used to establish linkage groups. Map distances (cM) were converted using recombination frequencies through the Kosambi mapping function. The visualised linkage maps were subsequently drawn using MapChart 2.2 [79].

\section{Cold hardiness QTL mapping and candidate gene identification}

The LTP and LTX (mean value of three replicates per genotype) in 2016, 2017, 2018 and the transformed phenotypic values were used separately for QTL mapping. Interval mapping (IM) and Multiple QTL mapping (MQM) method (four-way cross format) were used for integrated map based on the R/qtl package [80]. Genome wide $(\mathrm{GW})$ LOD threshold $(\alpha=0.5)$ were established through 1000 permutations of the phenotypic data and used for both IM and MQM QTL detection. QTLs with LOD score higher than GW LOD threshold were considered as significant ones. Firstly, IM analysis was conducted to find regions with potential QTL effects. Then, scored markers in these regions were used as cofactors in MQM analysis (max.qtl was set to 10 for forward selection). Genome scans were performed with a $1 \mathrm{cM}$ step. Markers which flanked or located at the peak LOD of a QTL were recognised as co-segregated markers. The explained phenotypic variation of each QTL $\left(R^{2}\right)$ was estimated using the "fitqtl" function. 1LOD confidence interval which corresponded to $95 \%$ confidence interval was calculated using the "lodint" function [81]. Candidate genes research was conducted based on the confidence interval (CI) of each QTL on integrated map. Genes were selected according to $12 \mathrm{X}$ V1 versions (Grape Genome Database, http://genomes. cribi.unipd.it/DATA/). A gene ontology (GO) enrichment analysis was performed for these identified genes using the "singular enrichment analysis" tool in the GO Analysis Toolkit and Database (http://bioinfo.cau.edu. $\mathrm{cn}$ /agriGO). The statistical significance of functional enrichment within the intervals was evaluated using the hypergeometric distribution, and the significant of GO terms was $P<0.05$.

\section{Supplementary information}

Supplementary information accompanies this paper at https://doi.org/10. 1186/s12864-020-06836-z.

Additional file 1: Data S1. The phenotypic data used in this study.

Additional file 2: Figure $\mathbf{S 1}$. Clean read number and average sequencing depth distribution of the 181 hybrid offspring.

Additional file 3: Data S2. Markers used for genetic linkage map construction.

Additional file 4: Data S3. The Mendelian segregation and depth of each marker

Additional file 5: Data S4. Marker number statistics of female, male and integrated map.

Additional file 6: Data S5. Bin markers of female, male and integrated map.

Additional file 7: Figure S2. Marker distribution and genetic length in 19 linkage groups of female parent 'Cabernet sauvignon'.

Additional file 8: Figure S3. Marker distribution and genetic length in 19 linkage groups of male parent 'Zuoyouhong'.

Additional file 9: Data S6. BLUP values of LTP and LTX used for QTL mapping.

Additional file 10: Data S7. Candidate genes involved in the confidence intercal of QTL mapping.

Additional file 11: Figure S4. Gene ontology (GO) enrichment analysis for gnes involved in stable QTL regions.

Additional file 12: Data S8. Spearman coefficient and map coverage of integrated map.

Additional file 13: Figure S5. Haplotyp maps of integrated map. Additional file 14: Figure S6. Heat maps of integrated map.

\section{Abbreviations}

QTL: Quantitative trait loci; RAD: Restriction-site associated DNA sequencing; SNP: Single-nucleotide polymorphism; MAS: Marker-assisted selection; NGS: Next-generation sequencing; GWAS: Genome-wide association study; LTP: Lethal temperature of phloem; LTX: Lethal temperature of xylem; LOD: Logarithm of odds; BLUP: Best linear unbiased predictor; GBS: Genotyping by sequencing; SLAF: Specific locus amplified fragment sequencing; DRE: Dehydration-responsive element; CSN: COP9 signalosome; COR: Cold-regulated genes; IM: Interval mapping; MQM: Multiple QTL mapping; Cl: Confidence interval

\section{Acknowledgements}

The English language editing in this article was supported by editage.

\section{Authors' contributions}

YG and XG contributed to experimental design and KS performed the experiments and wrote the article. HX and FZ performed cold hardiness detection and ZL and $\mathrm{KL}$ contributed to data analysis. All authors have read and approved the manuscript. 


\section{Funding}

This work was supported by the National Natural Science Foundation of China (Grant No. 31372021, 31572085), China Agriculture Research System (Grant No. CARS-29-yc-6), Shenyang Science and Technology Development Funds (Grant No. 18-013-0-35), and Research project in Liaoning Province Science and Technology Department (Grant No. LNKTP2016). Funding bodies were not involved in the design of the study and collection, analysis, interpretation of data and in writing the manuscript.

\section{Availability of data and materials}

The data supporting the results presented in this article are included as additional files. The raw sequencing data were deposited at the NCBI Sequence Read Archive (SRA) with the accession Number SRP266857.

\section{Ethics approval and consent to participate}

Not applicable.

\section{Consent for publication}

Not applicable.

\section{Competing interests}

The authors declare no competing interests.

\section{Author details}

${ }^{1}$ College of Horticulture, Shenyang Agricultural University, Shenyang, P.R. China. ${ }^{2}$ National \& Local Joint Engineering Research Center of Northern Horticultural Facilities Design \& Application Technology, Shenyang, P.R. China. ${ }^{3}$ College of Horticulture Science and Engineering, Shandong Agricultural University, Shandong, P.R. China.

Received: 15 January 2020 Accepted: 16 June 2020

Published online: 22 June 2020

\section{References}

1. Levitt J. Responses of plants to environmental stress. Chilling, freezing, and high temperature stresses. New York: Academic; 1980.

2. Fennell A. Freezing tolerance and injury in grapevines. J Crop Improv. 2004; 10:201-35

3. Guo YS, Shi GL, Liu ZD, Zhao YH, Yang XX, Zhu JC, et al. Using specific length amplified fragment sequencing to construct the high-density genetic map for Vitis (Vitis vinifera L.XVitis amurensis Rupr.). Front Plant Sci. 2015;6:393.

4. Jiang J, Fan X, Zhang Y, Tang X, Li X, Liu C, et al. Construction of a Highdensity genetic map and mapping of firmness in grapes (Vitis vinifera $L$.) based on whole-genome resequencing. Int J Mol Sci. 2020;21(3):797.

5. Smith HM, Clarke CW, Smith BP, Carmody BM, Thomas MR, Clingeleffer PR, et al. Genetic identification of SNP markers linked to a new grape phylloxera resistant locus in Vitis cinerea for marker-assisted selection. BMC Plant Biol. 2018;18(1):360

6. Sapkota S, Chen LL, Yang S, Hyma KE, Cadle-Davidson L, Hwang CF. Construction of a high-density linkage map and QTL detection of downy mildew resistance in Vitis aestivalis-derived 'norton'. Theor Appl Genet. 2019; 132(1):137-47.

7. Weeden NF, Hemmat M, Lawson DM, Lodhi M, Bell RL, Manganaris AG, et al. Development and application of molecular marker linkage maps in woody fruit crops. Euphytica. 1994;77(1-2):71-5.

8. Hyma KE, Barba P, Wang M, Londo JP, Acharya CB, Mitchel SE, et al. Heterozygous Mapping Strategy (HetMappS) for high resolution genotyping-by-sequencing markers: a case study in grapevine. PLoS One. 2015;10(8):e0134880

9. Guo F, Yu H, Tang Z, Jiang $X$, Wang $L$, Wang $X$, et al. Construction of a SNPbased high-density genetic map for pummelo using RAD sequencing. Tree Genet Genomes. 2015;11(1):2

10. Teh SL, Fresnedo-Ramírez J, Clark MD, Gadoury DM, Sun Q, Cadle-Davidson $L$, et al. Genetic dissection of powdery mildew resistance in interspecific half-sib grapevine families using SNP-based maps. Mol Breed. 2017;37(1):1.

11. Wang J, Su K, Guo Y, Xing H, Zhao Y, Liu Z, et al. Construction of a highdensity genetic map for grape using specific length amplified fragment (SLAF) sequencing. PLoS One. 2017;12(7):e0181728.
12. Zhu JC, Guo YS, Su K, Liu ZD, Li K, Guo XW. Construction of a highly saturated genetic map for Vitis by next-generation restriction site-associated DNA sequencing. BMC Plant Biol. 2018;18(1):347.

13. Tello J, Roux C, Chouiki H, Laucou V, Sarah G, Weber A, et al. A novel highdensity grapevine (Vitis vinifera L.) integrated linkage map using GBS in a half-diallel population. Theor Appl Genet. 2019;132(8):2237-52.

14. Barchi L, Lanteri S, Portis E, Acquadro A, Valè G, Toppino L, et al. Identification of SNP and SSR markers in eggplant using RAD tag sequencing. BMC Genomics. 2011;12:304.

15. Chutimanitsakun Y, Nipper RW, Cuesta-Marcos A, Cistué L, Corey A, Filichkina T, et al. Construction and application for QTL analysis of a Restriction Site Associated DNA (RAD) linkage map in barley. BMC Genomics. 2011;12:4.

16. Wang $\mathrm{N}$, Fang $\mathrm{L}$, Xin H, Wang L, Li S. Construction of a high-density genetic map for grape using next generation restriction-site associated DNA sequencing. BMC Plant Biol. 2012;12:148.

17. Wu J, Li LT, Li M, Khan MA, Li XG, Chen $H$, et al. High-density genetic linkage map construction and identification of fruit-related QTLs in pear using SNP and SSR markers. J Exp Bot. 2014;65(20):5771-81.

18. Sun $R$, Chang Y, Yang F, Wang Y, Li H, Zhao Y, et al. A dense SNP genetic map constructed using restriction site-associated DNA sequencing enables detection of OTLs controlling apple fruit quality. BMC Genomics. 2015:16:747.

19. Hua Y, Wei CL, Liu HW, Wu JL, Li ZG, Liang Z. Genetic divergence between Camellia sinensis and its wild relatives revealed via genome-wide SNPs from RAD sequencing. PLoS One. 2016;11(3):e0151424.

20. Wang L, Xia Q, Zhang Y, Zhu X, Zhu X, Li D, et al. Updated sesame genome assembly and fine mapping of plant height and seed coat color QTLs using a new high-density genetic map. BMC Genomics. 2016;17:31.

21. Wosula EN, Wenbo C, Zhangjun F, Legg JP. Unravelling the genetic diversity among Cassava Bemisia tabaci whiteflies using next RAD sequencing. Genome Biol Evol. 2017:9:2958-73.

22. Fischer BM, Salakhutdinov I, Akkurt M, Eibach R, Edwards KJ, Töpfer R, et al. Quantitative trait locus analysis of fungal disease resistance factors on a molecular map of grapevine. Theor Appl Genet. 2004;108(3):501-15.

23. Barker $\mathrm{CL}$, Donald T, Pauquet J, Ratnaparkhe MB, Bouquet A, Adam-Blondon $A F$, et al. Genetic and physical mapping of the grapevine powdery mildew resistance gene, Run1, using a bacterial artificial chromosome library. Theor Appl Genet. 2005;111(2):370-7.

24. Coleman C, Copetti D, Capriani G, Hoffmann S, Kozma P, Kovács L, et al. The powdery mildew resistance gene REN1 co-segregates with an NBS-LRR gene cluster in two central Asian grapevines. BMC Genet. 2009;10:89.

25. Zyprian E, Ochssner I, Schwander F, Simon S, Hausmann L, Bonow-Rex M, et al. Quantitative trait loci affecting pathogen resistance and ripening of grapevines. Mol Gen Genomics. 2016;291(4):1573-94.

26. Marguerit E, Boury C, Manicki A, Donnart M, Butterlin G, Némorin A, et al. Genetic dissection of sex determinism, inflorescence morphology and downy mildew resistance in grapevine. Theor Appl Genet. 2009;118(7):1261-78.

27. Divilov K, Barba P, Cadle-Davidson L, Reisch Bl. Single and multiple phenotype QTL analyses of downy mildew resistance in interspecific grapevines. Theor Appl Genet. 2018;131(5):1133-43.

28. Lin H, Leng H, Guo YS, Satoru K, Zhao YH, Shi GL, et al. QTLs and candidate genes for downy mildew resistance conferred by interspecific grape ( $V$. vinifera L. $\times$ V. amurensis Rupr.) crossing. Sci Hortic. 2019;244:200-7.

29. Krivanek AF, Riaz S, Walker MA. Identification and molecular mapping of $P d R 1$, a primary resistance gene to Pierce's disease in Vitis. Theor Appl Genet. 2006:112(6):1125-31.

30. Riaz S, Krivanek AF, Xu K, Walker MA. Refined mapping of the Pierce's disease resistance locus, $P d R 1$, and sex on an extended genetic map of Vitis rupestris $\times$ V. arizonica. Theor Appl Genet. 2006;113(7):1317-29.

31. Riaz S, Tenscher AC, Rubin J, Graziani R, Pao SS, Walker MA. Fine-scale genetic mapping of two Pierce's disease resistance loci and a major segregation distortion region on chromosome 14 of grape. Theor Appl Genet. 2008;117(5):671-81.

32. Barba P, Lillis J, Luce RS, Travadon R, Osier M, Baumgartner K, et al. Two dominant loci determine resistance to Phomopsis cane lesions in $\mathrm{F}_{1}$ families of hybrid grapevines. Theor Appl Genet. 2018;131(5):1173-89.

33. Doligez A, Bouquet A, Danglot Y, Lahogue F, Riaz S, Meredith CP, et al. Genetic mapping of grapevine (Vitis vinifera L.) applied to the detection of QTLS for seedlessness and berry weight. Theor Appl Genet. 2002;105(5):780-95.

34. Costantini L, Battilana J, Lamaj F, Fanizza G, Grando MS. Berry and phenology-related traits in grapevine (Vitis vinifera L.): from quantitative trait loci to underlying genes. BMC Plant Biol. 2008;8:38. 
35. Battilana J, Costantini L, Emanuelli F, Sevini F, Segala C, Moser S, et al. The 1-deoxyD-xylulose 5-phosphate synthase gene co-localizes with a major QTL affecting monoterpene contentin grapevine. Theor Appl Genet. 2009;118(4):653-69.

36. Emanuelli F, Battilana J, Costantini L, Cunff $L L$, Boursiquot JM, This $P$, et al. A candidate gene association study on muscat flavor in grapevine (Vitis vinifera L.). BMC Plant Biol. 2010;10:241.

37. Ban Y, Mitani N, Hayashi T, Sato A, Azuma A, Kono A, et al. Exploring quantitative trait loci for anthocyanin content in interspecific hybrid grape (Vitis labruscana $\times$ Vitis vinifera). Euphytica. 2014;198(1):101-14.

38. Carreño I, Antonio Cabezas J, Martínez-Mora C, Arroyo-García R, José LC, Martínez-Zapater JM, et al. Quantitative genetic analysis of berry firmness in table grape (Vitis vinifera L.). Tree Genet Genomes. 2015;11(1):818.

39. Fournier LA, Cunff LL, Doligez A, Ageorges A, Souquet JM, Cheynier V, et al. New insight into the genetics of color in grape. Acta Hortic. 2014;1046:59.

40. Chen J, Wang N, Fang LC, Liang ZC, Li SH, Wu BH. Construction of a highdensity genetic map and QTLs mapping for sugars and acids in grape berries. BMC Plant Biol. 2015;15:28.

41. Nicolas SD, Péros JP, Lacombe T, Launay A, Le Paslier MC, Bérard A, et al, Genetic diversity, linkage disequilibrium and power of a large grapevine (Vitis vinifera $\mathrm{L}$ ) diversity panel newly designed for association studies. BMC Plant Biol. 2016;16:74.

42. Migicovsky Z, Sawler J, Gardner KM, Aradhya MK, Prins BH, Schwaninger HR, et al. Patterns of genomic and phenomic diversity in wine and table grapes. Hortic Res. 2017;4:17035.

43. Yang X, Guo YS, Zhu JC, Niu ZZ, Shi GL, Liu ZD, et al. Genetic diversity and association study of aromatics in grapevine. J Am Soc Hortic Sci. 2017;142:225-31.

44. Guo DL, Zhao HL, Li Q, Zhang GH, Jiang JF, Liu CH, et al. Genome-wide association study of berry-related traits in grape [Vitis vinifera L.] based on genotyping-by-sequencing markers. Hortic Res. 2019;6:11.

45. Correa J, Mamani M, Muñoz-Espinoza C, Laborie D, Muñoz C, Pinto M, et al. Heritability and identification of QTLs and underlying candidate genes associated with the architecture of the grapevine cluster (Vitis vinifera L.) Theor Appl Genet. 2014;127(5):1143-62.

46. Fanizza G, Lamaj F, Costantini L, Chaabane R, Grando MS. QTL analysis for fruit yield components in table grapes (Vitis vinifera). Theor Appl Genet. 2005;111(4):658-64.

47. Laucou V, Launay A, Bacilieri R, Lacombe T, Adam-Blondon AF, Bérard A, et al. Extended diversity analysis of cultivated grapevine Vitis vinifera with 10K genome-wide. PLoS One. 2018;13(2):e0192540.

48. Doligez A, Bertrand Y, Farnos M, Grolier M, Romieu C, Esnault F, et al. New stable QTLs for berry weight do not colocalize with QTLs for seed traits in cultivated grapevine (Vitis vinifera L.). BMC Plant Biol. 2013;13:217.

49. Fechter I, Hausmann L, Daum M, Sörensen TR, Viehöver $P$, Weisshaar B, et al. Candidate genes within a $143 \mathrm{~kb}$ region of the flower sex locus in Vitis. Mol Gen Genomics. 2012;287(3):247-59.

50. Battilana J, Lorenzi S, Moreira FM, Moreno-sanz P, Failla O, Emanuelli F, et al. Linkage mapping and molecular diversity at the flower sex locus in wild and cultivated grapevine reveal a prominent SSR haplotype in hermaphrodite plants. Mol Biotechnol. 2013;54(3):1031-7.

51. Doligez A, Bertrand Y, Dias S, Grolier M, Ballester JF, Bouquet A, et al. QTLs for fertility in table grapes (Vitis vinifira L.). Tree Genet Genomes. 2010;6(3):413-22.

52. Duchêne $E$, Butterlin $B$, Dumas $V$, Merdinoglu $D$. Towards the adaptation of grapevine varieties to climate change: QTLs and candidate genes for developmental stages. Theor Appl Genet. 2012;124(4):623-35.

53. Wataru T, Yuichi M, Tohru S, Tadashi T. Identification of a novel major locus for gray leaf spot resistance in Italian ryegrass (Lolium multiflorum Lam.). BMC Plant Biol. 2014;14:303.

54. Giovanny C. Genome-assisted prediction of quantitative traits using the R package sommer. PLoS One. 2016;11(6):e0156744.

55. Londo JP, Johnson LM. Variation in the chilling requirement and bud burst rate of wild Vitis species. Environ Exp Bot. 2014;106:138-47.

56. Londo JP, Kovaleski AP. Characterization of wild north American grapevine cold hardiness using differential thermal analysis. Am J Enol Viticult. 2017;68:203-12.

57. Pierquet $P$, Stushnoff $C$. Relationship of low temperature exotherms to cold injury in Vitis riparia Michx. Am J Enol Viticult. 1980;31:1-6.

58. Ketchie DO, Kammereck R. Seasonal variation of cold resistance in Malus woody tissue as determined by differential thermal analysis and viability tests. Can J Bot. 1987;65(12):2640-5.

59. Lindstrom OM, Anisko T, Dirr MA. Low-temperature exotherms and cold hardiness in three taxa of deciduous trees. J Amer Soc Hort Sci. 1995;120:830-4.
60. Clark JR, Wolf TK, Warren MK. Thermal analysis of dormant buds of two muscadine grape cultivars and of Vitis labrusca L.'Mars'. HortScience. 1996; 31:79-81.

61. Volk GM, Waddell J, Towill L. Variation in low-temperature exotherms of pecan cultivar dormant twigs. HortScience. 2009;44:317-21.

62. Canaguier A, Grimplet J, Di Gaspero G, Scalabrin S, Duchêne E, Choisne N, et al. A new version of the grapevine reference genome assembly (12X.v2) and of its annotation (VCost.v3). Genom Data. 2017;14:56-62.

63. Sun X, Liu D, Zhang X, Li W, Liu H, Hong W, et al. SLAF-seq: an efficient method of large-scale de novo SNP discovery and genotyping using highthroughput sequencing. PLoS One. 2013;8(3):e58700.

64. Liu D, Ma C, Hong W, Huang L, Liu M, Liu H, et al. Construction and analysis of high-density linkage map using high-throughput sequencing data. PLoS One. 2014;9(6):e98855.

65. Shao C, Niu Y, Rastas P, Liu Y, Xie Z, Li H, et al. Genome-wide SNP identification for the construction of a high-resolution genetic map of Japanese flounder (Paralichthys olivaceus): applications to QTL mapping of Vibrio anguillarum disease resistance and comparative genomic analysis. DNA Res. 2015;22(2):161-70.

66. Viana AP, Riaz S, Walker MA. Genetic dissection of agronomic traits within a segregating population of breeding table grapes. Genet Mol Res. 2013;12(2):951-64.

67. Beavis $\mathbf{W}$. The power and deceit of QTL experiments: lessons from comparative QTL studies. In: Proceedings of the Forty-Ninth Annual Corn and Sorghum Industry Research Conference; 1994. p. 49.

68. Göring HH, Terwilliger JD, Blangero J. Large upward bias in estimation of locus-specific effects from genomewide scans. Am J Hum Genet. 2001;69(6): 1357-69.

69. Slate J. From beavis to beak color: a simulation study to examine how much QTL mapping can reveal about the genetic architecture of quantitative traits. Evolution. 2013;67(5):1251-62.

70. Yamaguchi-Shinozaki K, Shinozaki K. Transcriptional regulatory networks in cellular responses and tolerance to dehydration and cold stresses. Annu Rev Plant Biol. 2006:57:781-803.

71. Stockinger EJ, Gilmour SJ, Thomashow MF. Arabidopsis thaliana CBF1 encodes an AP2 domain-containing transcriptional activator that binds to the C-repeat/DRE, a cis-acting DNA regulatory element that stimulates transcription in response to low temperature and water deficit. Proc Natl Acad Sci U S A. 1997;94(3):1035-40.

72. Schwechheimer C, Serino G, Deng XW. Multiple ubiquitin ligase-mediated processes require COP9 signalosome and AXR1 function. Plant Cell. 2002; 14(10):2553-63.

73. Maruyama K, Sato N, Ohta N. Conservation of structure and cold-regulation of RNA-binding proteins in cyanobacteria: probable convergent evolution with eukaryotic glycine-rich RNA-binding proteins. Nucleic Acids Res. 1999; 27(9):2029-36.

74. Manival X, Ghisolfi-Nieto L, Joseph G, Bouvet P, Erard M. RNA-binding strategies common to cold-shock domain- and RNA recognition motifcontaining proteins. Nucleic Acids Res. 2001;29(11):2223-33.

75. Sun X, Tomás MJ, Chern JWD, Wang Z, Chai F, Zhang L, et al. The GARP/ MYB -related grape transcription factor AQUILO improves cold tolerance and promotes the accumulation of raffinose family oligosaccharides. J Exp Bot. 2018;69(7):1749-64.

76. Hanania U, Velcheva M, Sahar N, Perl A. An improved method for isolating high-quality DNA from Vitis vinifera nuclei. Plant Mol Biol Rptr. 2004;22(2):173-7.

77. Li H, Durbin R. Fast and accurate short read alignment with burrowswheeler transform. Bioinformatics. 2009;25(14):1754-60.

78. McKenna A, Hanna M, Banks E, Sivachenko A, Cibulskis K, Kernytsky A, et al. The genome analysis toolkit: a Mapreduce framework for analyzing nextgeneration DNA sequencing data. Genome Res. 2014;20(9):1297-303.

79. Voorrips RE. MapChart: software for the graphical presentation of linkage maps and QTLs. J Hered. 2002;93(1):77-8.

80. Broman KW, Wu H, Sen $\AA$, Churchill GA. R/qtl: QTL mapping in experimental crosses. Bioinformatics. 2003;19(7):889-90.

81. Huang YF, Doligez A, Fournier-Level A, Le Cunff L, Bertrand Y, Canaguier A, et al. Dissecting genetic architecture of grape proanthocyanidin composition through quantitative trait locus mapping. BMC Plant Biol. 2012;12:30.

\section{Publisher's Note}

Springer Nature remains neutral with regard to jurisdictional claims in published maps and institutional affiliations. 